\title{
User-centered ecotourism development
}

\author{
Talsma, L, ${ }^{\mathrm{a}, *}$, Molenbroek, J.F.M, ${ }^{\mathrm{b}}$ \\ ${ }^{\text {a }}$ The User's Advocate, Delft \\ ${ }^{\mathrm{b}}$ Faculty of Industrial Design Engineering, Delft University of Technology
}

\begin{abstract}
The transfer of knowledge in an ecotourism project is never a one-way affair. An approach connected to bottomup development is the submersion into another culture, while creating a new organizational structure. For co-creation, patterns that are often latent, such as leadership roles, the association with business, or even the color of education can be revealed by carefully facilitated brainstorms or workshops. Especially in countries with a different hierarchical structure, such as Indonesia compared to Holland, a careful analysis is needed before starting cooperation. Although a case is only a temporary view on a situation and not a guarantee for a truly sustainable system, the bottom-up approach tested has interesting starting points for an ecotourism system. Two cases were conducted in Bali, Indonesia, which resulted in guidelines on how to approach usercentered ecotourism development.
\end{abstract}

Keywords: Eco-tourism, sustainability, cultural diversity, co-creation, participatory research, developing countries

\section{Introduction}

Ecotourism as a definition started off being based on the ecological aspects attributed to a certain kind of tourism; the benefits to nature while making nature accessible to visitors. Cultural ecotourism or social tourism only started occurring later, as a result of the diminishing of cultural or indigenous activity in a region. In order to develop ecotourism a location has to have some attractions to visitors, but what is needed from a population to effectively manage ecotourism, and how can it be built up from existing structures in order to create ownership and responsibility?

The development of ecotourism in a village or region is a complex situation, which asks for a suitable working method and team. The change management needed to improve the situation in a village is often aimed towards factors such as economy or nature, while the situation should be evaluated holistically. This paper introduces a way to initiate the transition towards ecotourism in a village of area based on the demands of its users and possibilities that are already present. This different perspective, developing ecotourism bottom-up instead of only top-down, requires new methods of interacting and analyzing.

Ecotourism is on a small scale a means to truly celebrate nature and culture at a location, while at the same time being the motor to maintain or even improve that situation. On a different scale this could also be applied to businesses, which are naturally a motor, but often need to change to improve their surroundings and offset.

\section{Problem statement:}

Ecotourism projects organized only top-down, without the input from bottom-up are not a sustainable solution over time.

Often heard problems in the development of ecotourism are lack of ownership, short term thinking, little market orientation and a possible negative influence on nature and society.

Some people would say all that can be helped by proper education and learning. Learning, however, can only by accomplished when people are willing to and see that it benefits their livelihood. This paper illustrates what is behind the development of ecotourism; what kind of people are needed to set it up, how is that influenced by local culture

* Corresponding author. The User's Advocate, Cornelis Musiusstraat 2, Delft.laura@theusersadvocate.com, tel. +31620050927. 
and can the problems noted above be altered slightly by a more bottom-up approach as opposed to the top-down western views which are now often imposed in developing countries.

WWF on ecotourism: There are many reported incidents where forms of 'ecotourism', which are not sufficiently community focused, are having a negative impact on the environment, and where indigenous communities are not receiving sufficient benefit. Moreover, many small-scale communitybased ecotourism initiatives have been set up which have failed owing to a lack of market assessment, organization, quality and promotion ${ }^{l}$.

It is in the local communities where ecotourism occurs, as the communities are the destination of most travellers ${ }^{2}$. Thus, local people in the area of these destinations are not only closely influenced by tourism, but they are expected to be part of the tourism product ${ }^{3}, 4$. Their understanding of local dynamics enables them to identify issues of local concern, determine the utilization of local materials and resources and the pace and scale of development ${ }^{5}$. In turn, community involvement was found to be positively related to the residents' attitudes towards tourism ${ }^{6}$, which is prerequisite for additional development. A failure to involve the local community in the decision making process and the lack of integrated vision at the regional level of tourism planning form major barriers towards achieving sustainability $^{7}$.

The term users and user-centered in this case, needs some explanation. Where the visitors are quite clear users of an ecotourism system, the village organizing ecotourism is and should be seen as the users of the system too. Since the ecotourism benefits not only tourists but also especially the village, the necessary focus and ownership should be built in order to make it continuous and beneficial.

When basing ecotourism on the users, not only clients but also the villagers involved, quite some research has to be done in the forefront of the tourism development, see figure 1 . In a simplified scheme of the process, the focus of this method is on the forefront of the process, assessing a situation and starting to create a new tourism destination of it.

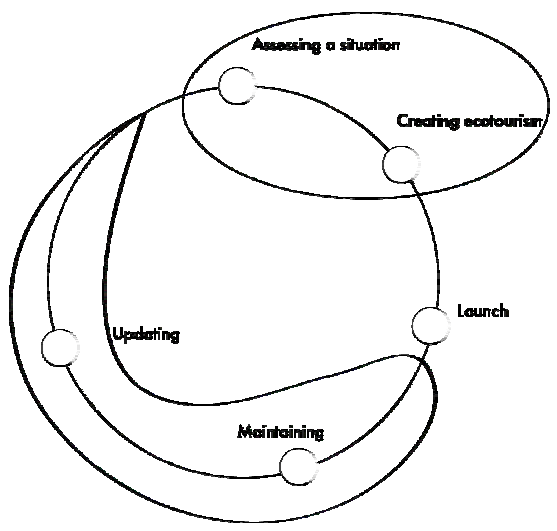

Figure 1

Orientation of the article in the ecotourism development process

\section{Assessing a situation for bottom-up development}

When developing an ecotourism project, it is very important to assess what is already present in a village or area, before changing it, so the project can be built on structures instead of making new ones.

The situation presents the problem definition, which is a base of a solution. A framework is made to allocate the disruptions in the system, and evaluate how they could be changed by ecotourism.

\subsection{Allocating disruptions and possibilities in the existing system}

In an ideal situation, ecology, economy and society are strengthening each other, and balanced. In most situations, there are disruptions between the three.

'Conventional' ecotourism has mostly been based on outstanding natural attractions, while a combination of the three factors is a better base to start from. Not only the strengths should be used as a starting point, also the weaknesses should be addressed to improve a situation. 


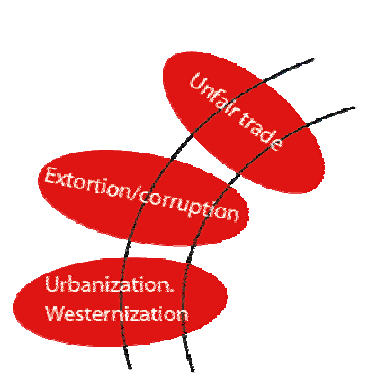

People

Culture

Society

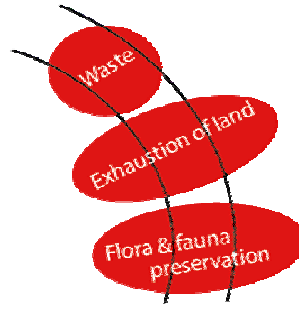

Economy

Nature

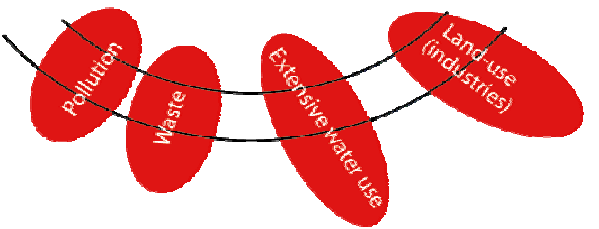

Figure 2

The model for assessing a situation for ecotourism - negative attributes
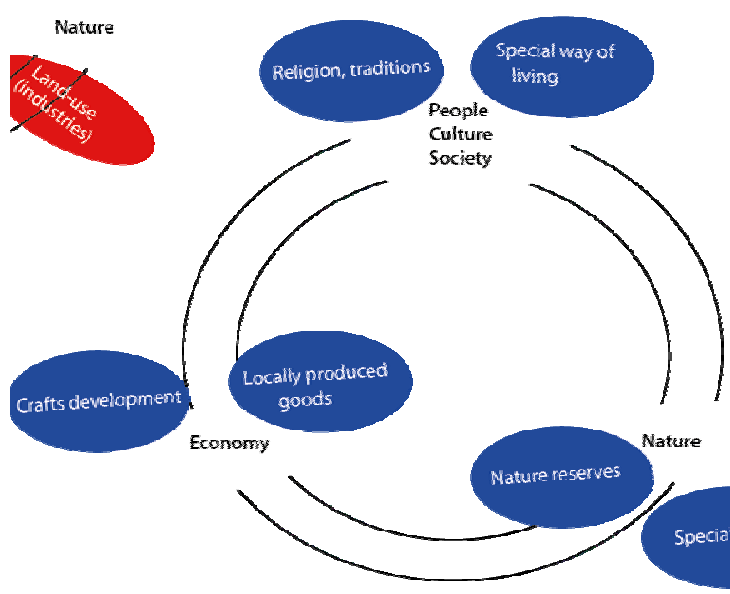

Special animals

Figure 3

The model for assessing a situation for ecotourism - possibilities for ecotourism
Some of the disruptions and possibilities that often occur explained:

Waste - a lack of a suitable waste system, which causes the disposal of a lot of household- or even industrial waste in nature. Some waste causes health risks and non-biodegradable materials pollute nature, amongst other harms

Corruption - a topic too complex to quickly summarize; in this situation corruption is often causing people without (political) influence to be extorted, or maltreated, not getting the chance they deserve.

Culture decay - depending on the culture, traditional cultures are often built on elaborate ceremonies, traditions and conventions around the community. When members are forced to leave the community to earn their living, there is little or no time for cultural expressions.

Urbanization - people want to or are forced to move to cities for a better income. It is estimated that by the year 2050, one third of the world population will thus live as a land-squatter, in slums near cities $^{8}$, with a lot less options than in rural areas.

'Westernization' - 'old' cultures are often not appreciated anymore by youngsters in developing countries, and western models of capitalism and individual enrichment are copied, while they are more suitable and constructive models for a nonwestern situation.

\subsection{Allocation of needs from (future) visitors}

Besides the possibilities present at the location where ecotourism is developed, a clear understanding should be obtained regarding the demands of visitors. This demand is not absolute; it varies depending on the offer of other (eco-)tourism venues close by and the type of visitors coming, both of which might change over time.

As illustrated above, both the disruptions in the cycle and the strengths and possibilities should be taken into account when making a plan for ecotourism. The disruptions should be addressed by education or given a value by clear income because of ecotourism. 
Some of the most important factors in the research on visitors:

Time

- Distance of ecotourism to their accommodation

- Amount of time willing to spend on activities

- How can the expected stay of tourists be elongated

\section{Organization}

- Understanding and acceptance of sustainable tourism

- Level of organization; is the destination organized for them/by them

- Information gathering; what sources are trusted by tourists, where do they get their information

\subsection{Cultural diversity}

One very important part of the assessment is the people; not only can there be possibilities or difficulties in its links with planet and profit, the people are also the vital factor in the success of ecotourism. Since this paper is aimed at the bottom-up development of ecotourism, people are centered.

Within personalities, a distinction can be made to what is culturally based, and what is personality ${ }^{9}$. Especially in eco-tourism, where different cultures meet, both tiers should be taken into account.

Cultures, as described by Hofstede ${ }^{10}$, have different values in the following categories:

- Power Distance Index

- Individualism

- Masculinity

- Uncertainty avoidance index

- $\quad$ Long Term Orientation

All of these factors have their effects on the setup of an organization. Most countries are listed on the website of Hofstedes cultural dimensions ${ }^{11}$ with a national profile on these factors. There are, however, subcultures and different personalities, which should be taken into account while an ecotourism team is formed.
- What is perceived safe and comfortable; especially in rural areas tourists need a high level of security

\section{Program}

- Activities wanted

- Pricing

- Demographics; age, possible expenditures, family situation

Some of this information can be obtained by statistics on the destination or country information on their tourism industry. Quite a lot of information, however, can only be obtained by more qualitative studies, for instance on what is expected of ecotourism, the perceived advantage of it or what type of activities are wanted and in what setting.

These methods are discussed in the case studies.

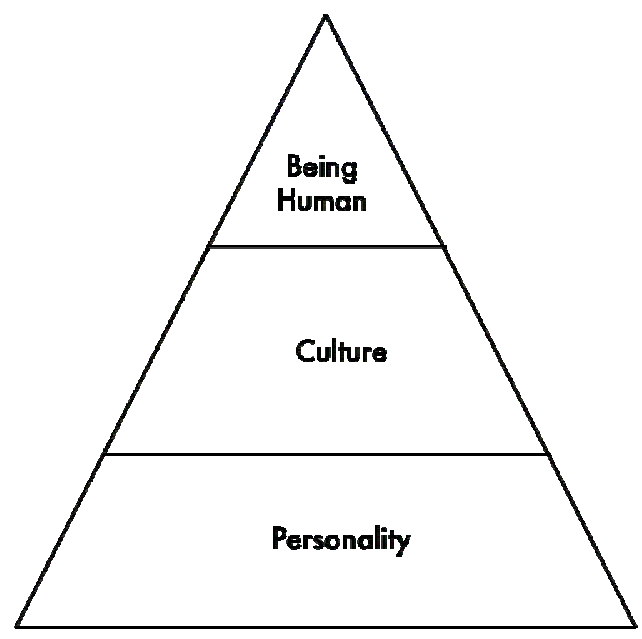

Figure 4

The levels of culture ${ }^{12}$ 


\section{Case studies}

\subsection{Methodology}

Two case studies were conducted and evaluated, both on Bali, Indonesia. The Dutch foundation Ergindo, founded by members of the ergonomics staff of Delft University of Technology sent students with the aim of transferring ergonomic knowledge to Indonesia in the development of ecotourism.

Four Dutch students contributed to this project by organizing and constructing the Bali trail, walking trails in Bali ${ }^{13}$ in the villages Petiga and Tampaksiring. Workshops were conducted for this research in cooperation with Prof. Emeritus Adnyana Manuaba, Udayana University, Denpasar, Bali.

Variance in their approach for organizational and structural ergonomics make the cases an interesting comparison, and a fertile ground for developing tools for other projects.

Two different situations were selected, one village with no existing initiative, where the top-down development overshadowed the bottom-up input. The other was already taking the initiative and was developed mainly bottom-up.

\section{Participatory approach}

In both cases, a participatory approach was used during the set-up of ecotourism, with varying techniques. The cultural aspects and context of the starting situation was mapped using context-mapping techniques ${ }^{14}$ adjusted to the occasion.

Observational research was done by several students, as well as occasional interviews, in combination with workshops with Dutch students, Indonesian students and villagers alike.

Throughout the process an action research approach was taken, developing partial solutions and testing them with end users, while developing

\subsection{Bali Trail: Petiga}

Petiga is a small village in the center of Bali, quite far from the busy tourist activity in the southern part of the island. The main source of income of most villagers is the selling of plants to hotels and gardeners, combined with agriculture.

Ecotourism development started in the village because of connections to the university living in the village; there was no clear initiative from the village.

Four Dutch students worked on the Bali Trail project in Petiga, two mainly from a distance on an advisory role, two hands-on in the village, developing walking tracks and an ecotourism organization.

The approach used was mixed; one team member used a top-down approach, and designed the walking trails and other physical materials needed. The village team advised on what construction workers to use, which was not beneficial for the entire village.

One other team member focused on the organization needed for ecotourism and the knowledge that needed to be transferred, from a bottom-up (coaching) perspective.

The team worked on the development of the walking trails around the village, the instructions needed for guides, a small office to host people in, a school program aimed at education about waste, different kinds of signage, a bathroom and extensive team and organization building. Besides this, a schooling program was started for youngsters to learn English, which should be financed by some of the profit of the Bali Trail.

When all physical and informational materials had been developed, the trails were tested with tourists.

After the students left, little work was still put in the organization by the villagers. The walking trails are still used happily by the villagers, but hardly any tourists visit.

\subsection{Bali Trail: Tampaksiring}

The village of Tampaksiring is located quite close to Ubud, a main tourism hub in the island. The village is next to Tirta Empul, a beautiful temple with springs that is listed to be a Unesco world heritage site. Despite this, not many tourists know the village or stay there; there is some interest in the form of tourist excursions, but hardly any tourists stay longer than two hours. 
Dewa is a manager in a very well known restaurant in Ubud, en thus knows how to interact with guests and specify their needs. Dewa already took guests on small hiking trips, which was a motivation to work with him and try to develop this small scale business into a larger organization.

With Dewa as a leader of the program, the local youth organization was attracted to function as guides and caretakers, and the subak system (irrigation for the rice fields) got involved.

A waste program was set up, because there were no waste bins in the rice paddies and along the road where the tourists would pass. By clearing the irrigation canals of plastic, the farmers were helped and the area was cleaned up.

Bamboo huts were created from locally bought bamboo, so the visitors could rest halfway through their walk. Even a standalone toilet was made next to the most central hut.

Most of the walking trail installations (handrails, steps, ground reinforcement were made from local materials and preferably bamboo. When the trails would be used a lot, part-by-part the bamboo could be replaced by a more durable material. This would prevent the high investments on durable materials made in Petiga, which are not used to the fullest.

Both the organization and the physical materials were set up 'lean' - a lot of people were involved, but they would have other small jobs in case of little customers, which could be gradually phased out.

All the team members of the organization constructed the easy parts of the walking trails, assisted by carpenters on the harder parts. This created a clear feeling of ownership and contribution.

After finishing the constructions and training, some effort was put in the marketing of the Bali Trail. The team members in the village, however, are not very comfortable promoting the program, a culture related sentiment. The main step still to be taken is the proper marketing, possibly by people outside the village.

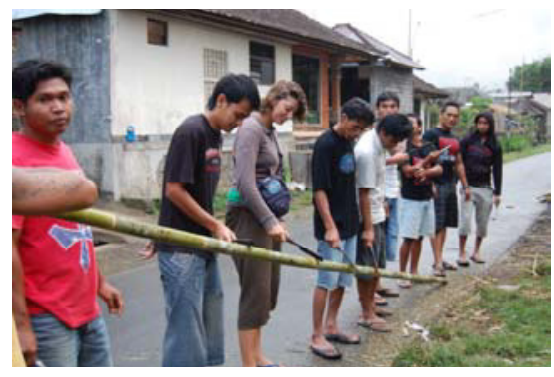

Figure 5

Creating the Bali Trail in Tampaksiring with the youth generation

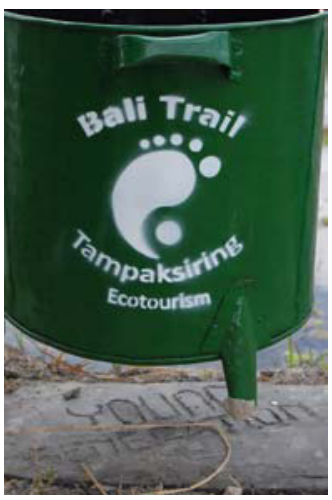

Figure 6

The waste removal project in Tampaksiring, installed and maintained by the youth generation

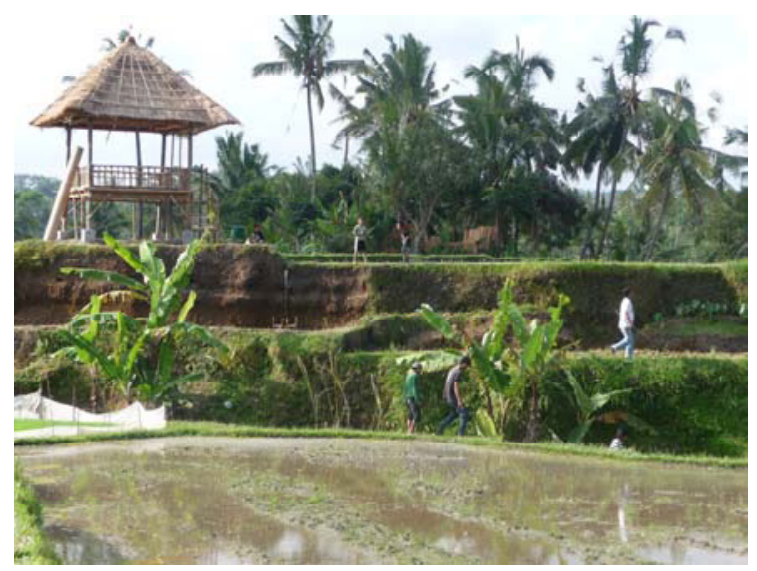

Figure 7

One of the huts made for the visitors to rest during their walk 


\section{Findings}

\subsection{Petiga}

Because the organization was not built from a present initiative in the first place, there was too little ownership and responsibility felt in the village team to actively participate. After the Dutch team left most of the walking trails were made and usable, the whole system practiced and prepared.

The village team had some troubles to cope with, which led to their inability to bring the Bali Trail to the next level, receiving customers:

- Ownership (or lack of it) / responsibility

- Relations within the village, the project was perceived as a personal thing, not supported by the whole village

- Leadership. One of the students took a 'boss' role, without that input the team was lacking a leadership role. Most of the people also wanted a leader, to be ordered around

- Initiative is needed to start off with and build on (but also needs to spread through a community). This was lacking in Petiga

- Political influence - is the project matching with the governmental ambitions? The village chief was in the project team, but did not arrange continuation

- Hierarchy, age and male are the three keywords of Indonesian culture as perceived in this case. Youngsters were either not included or not listened to, while they could have been helpful additions to the project team

\subsection{Tampaksiring}

Tampaksiring was a project developed with the insights from the Petiga case, which made it a lot more feasible.

Some findings in this case:

- Ownership is created through building up the project together, and starting with initiative

- The importance of local organizations: by including the youth organization and the subak system, the knowledge and trust of the village was obtained

- Collectivity in this village (and many others) caused the villagers to be wary of someone sticking out from the group. This risk was reduced by being extremely clear about financing, having it checked and talked about.
- Collectivity in this village also meant not promoting yourself openly; most of the youngsters were too shy to promote the project, marketing remained a fragile point in the project

- Hierarchy is clearly present in the Tampaksiring organization. One leader, which was clear for the rest. The follow-up, the leader of the youngsters, was already tagging along

\section{Concluding}

Knowledge of physical ergonomics cannot be transferred without first creating a valid organization and value proposition for villagers, when it comes to ecotourism. Basing the ecotourism program on the demands and specializations of the village acquires more ownership and a lasting solution instead of short-term profits as seen in conventional tourism projects.

The knowledge transfer which worked best in this project is by doing; villagers either were not able or did not want to read. Personal coaching and talking works much better.

Ecotourism projects organized only top-down, without the input from bottom-up are not a sustainable solution over time. As is illustrated by both cases, ownership can be created from the start, together with the other factors needed for continuation. Some knowledge is just not present in the villages, for instance about marketing - this is why both bottomup and top-down must be combined.

\section{References}

[1] WWF: www.wwf.com

[2] U. Blank, The community tourism industry imperative: The necessity, the opportunitintial. its potential. State College, PA: Venture Publishing, 1989

[3] R. Scheyvens, Ecotourism and empowerment of local communities. Tourism Management, 20(1999)2, 245-249.

[4] D.G. Simmons, Community participation in tourism planning. Tourism Management, 15 (1994), 2,98-108.

[5] K. Simpson, Strategic Planning and Community Involvement as contributors to sustainable tourism development. Current Issues in Tourism, 4 (2001)1, 3-41.

[6] E. Inskeep, Tourism planning: An integrated and sustainable development approach. New York, Van Nostrand Reinhold, 1991 
[7] A Flawed implementation of sustainable tourism : the experience of Akamas, Cyprus, Tourism Management, 16(1995)8, 583-592.

[8] R.Neuwirth, Shadow Cities; a billion squatters, a new urban world. Routlegde, New York, 2006

[9] G.J.Hofstede, Cultural Dimensions, www.geert-hofstede.com

[10] idem

[11] Idem

[12]

[13]www.balitrail.com

[14] F.Sleeswijk-Visser,P.J.Stappers, R.van der Lugt, EB-N Sanders, Contextmapping: Experiences from Practice, Delft University of Technology,2005 